\title{
The Impact of Geographic Proximity to Transplant Center on Outcomes after Allogeneic Hematopoietic Stem Cell Transplantation
}

\author{
Karim E. Abou-Nassar, MD ${ }^{1}$, Haesook T. Kim, $\mathrm{PhD}^{3}$, Jeff Blossom, MA ${ }^{4}$, Vincent T. Ho, \\ $M^{2}$, Robert J. Soiffer, MD2 ${ }^{2}$, Corey S. Cutler, MD, MPH${ }^{2}$, Edwin P. Alyea, MD², John Koreth, \\ MD, MBBS, DPhil ${ }^{2}$, Joseph H. Antin, MD², and Philippe Armand, MD, PhD² \\ ${ }^{1}$ Department of Medicine, Division of Hematology, University of Ottawa, The Ottawa Hospital, 501 \\ Smyth road, Ottawa, Ontario, Canada, K1H 8L6 \\ ${ }^{2}$ Department of Medical Oncology, Dana-Farber Cancer Institute, 44 Binney Street, Boston, \\ Massachusetts, USA, 02115. \\ ${ }^{3}$ Department of Biostatistics and Computational Biology, Dana-Farber Cancer Institute, 44 Binney \\ Street, Boston, Massachusetts, USA, 02115. \\ ${ }^{4}$ Center for Geographic Analysis, Harvard University, 1737 Cambridge Street, Cambridge, \\ Massachusetts, USA, 02138
}

\begin{abstract}
BACKGROUND-Patients undergoing allogeneic hematopoietic stem cell transplantation (HSCT) need access to specialized care. We hypothesized that access to the transplant center after HSCT may be challenging for patients living in geographically distant areas, and that this would have an adverse effect on their outcome.
\end{abstract}

METHODS-We analyzed 1912 adult patients who underwent allogeneic HSCT at DF/BWCC between 1996 and 2009 and who resided within 6 hours driving time of the institution. Driving time from primary residence to DF/BWCC based on zipcode was determined using geographic information systems.

RESULTS-The median driving time (range) to DF/BWCC was 72 (2-358) minutes. When patients were stratified by driving time quartile, overall survival (OS) after HSCT was similar in the first year but worse after 1 year in patients in the top quartile ( $\geq 160$ minutes driving time). In a landmark analysis of the 909 patients alive and free of disease at 1 year, 5-yr OS was $76 \%$ and $65 \%$ for patients in the $1^{\text {st }}$ ( $\$ 40$ minutes) and 4 th ( $\geq 160$ minutes) quartiles, respectively ( $\mathrm{p}=0.027$ ). This was confirmed in a multivariable analysis. The difference appeared to be mostly due to an increase in non-relapse mortality. The number of visits to the transplant center between day 100

(C) 2011 The American Society for Blood and Marrow Transplantation. Published by Elsevier Inc. All rights reserved.

Address correspondence to: Philippe Armand, MD, PhD Assistant Professor of Medicine, Harvard Medical School Dana-Farber Cancer Institute 450 Brookline Avenue Boston, MA 02215 617-632-2305 (office) 617-632-4422 (fax)

Philippe_armand@dfci.harvard.edu.

Publisher's Disclaimer: This is a PDF file of an unedited manuscript that has been accepted for publication. As a service to our customers we are providing this early version of the manuscript. The manuscript will undergo copyediting, typesetting, and review of the resulting proof before it is published in its final citable form. Please note that during the production process errors may be discovered which could affect the content, and all legal disclaimers that apply to the journal pertain.

Author Contributions: Drs Abou-Nassar and Armand had full access to all of the data in the study and take responsibility for the integrity of the data and the accuracy of the data analysis.

Disclosures: All authors have no relevant conflicts of interest to declare. 
and 365 after HSCT declined significantly with increasing driving time to the transplant center, which was independently associated with worse survival.

CONCLUSION-Long driving time to the transplant center is associated with worse OS in patients alive and disease-free one year after HSCT, independently of other patient-, disease- and HSCT related variables. This may be in part related to the lower frequency of post-HSCT visits in patients living farther away.

\section{INTRODUCTION}

Allogeneic hematopoietic stem cell transplantation (HSCT) is a potentially curative treatment modality used in the treatment of hematological malignancies. Despite major advances in supportive care, complications still result in significant treatment-related mortality. Moreover, many of the complications of HSCT, such as opportunistic infections, acute and chronic graft-versus-host disease (GVHD) are rarely seen outside of the HSCT setting. Their detection and management require high vigilance, a low threshold to intervene, and highly specialized knowledge [1]. As a result, HSCT is mostly performed in experienced and accredited transplant centers [2]. In other clinical settings, it has been shown that patients residing in rural areas have to travel considerably greater distances than their urban counterparts to access specialized care [3] resulting in differences in healthcare access and utilization [4;5]. This may be particularly relevant in the setting of HSCT where specialized care is paramount. Consequently, patients residing in geographically remote areas to the transplant center could potentially be at higher risk of adverse outcome after HSCT.

In a recent retrospective database study on patients undergoing HSCT in Nebraska, patients from rural areas undergoing autologous stem cell transplantation (ASCT) were found to have an $18 \%$ increased relative mortality rate compared to patients from urban areas [6]. Similar studies in the allogeneic setting have failed to demonstrate such an association, although they have been largely underpowered to detect survival differences. In the present study, we investigated if geographic proximity to the transplant center affects overall survival (OS) in a cohort of adult patients who underwent allogeneic HSCT at Dana-Farber/ Brigham and Women's Cancer Center (DF/BWCC).

\section{METHODS}

\section{Patients and data source}

We studied all consecutive adult patients who underwent allogeneic HSCT at DF/BWCC between 1/1/1996 and 6/30/2009. Zip code of residence at the time of transplantation for each patient included in this study was obtained using the Clinical Operations and Research Information Systems (CORIS) database at DF/BWCC. Each zipcode data point was geocoded using the ArcGIS 9.3 StreetMap North America Postal US address locater (ESRI, Redlands CA, USA). The location of DF/BWCC was geocoded into a separate map layer using the US Streets address locater. The ArcGIS Network Analyst extension (ESRI, Redlands CA, USA) was used to calculate driving distance and average driving time along the street network from zipcode of primary residence to DF/BWCC for each patient. The ESRI Business Analyst 2009 dataset (ESRI, Redlands CA, USA) was used to extract the median household income and other relevant census variables for each zipcode. The number of clinical encounters with HSCT providers at DF/BWCC after HSCT was obtained for each patient through the CORIS at DF/BWCC. Patients residing more than 6 hours driving time of the institution were excluded as they were likely to receive their post-HSCT care in another transplantation center. All clinical data was derived from the existing HSCT 
database at DF/BWCC. This study was approved by the institutional review board and conducted in accordance with the principles of the Declaration of Helsinki.

HSCT

Patients received allogeneic HSCT for numerous indications and under several treatment and investigational protocols at DF/BWCC over the 13-year period covered by this study. Both myeloablative and reduced-intensity conditioning regimens were included. Patients received bone marrow, peripheral-blood stem cells, or umbilical cord blood from matched or mismatched, related or unrelated donors. Acute GVHD (aGVHD) was graded according to the consensus scoring system [7]. Supportive care followed institutional guidelines or protocol requirements.

\section{Statistical analysis}

The primary objective of this retrospective study was to investigate if geographic proximity affects OS in this cohort. Patient baseline characteristics were reported descriptively, and compared using $\chi^{2}$ test or Kruskal-Wallis test. Overall survival and disease-free survival were calculated using the Kaplan-Meier method. Overall survival was defined as the time from stem cell infusion to death from any cause; those alive or lost to follow-up were censored at the date last known alive. Disease-free survival was defined as the time from stem cell infusion to disease relapse, progression or death from any cause, whichever occurred first. Patients who were alive without disease relapse or progression were censored at the time last seen alive and disease-free. The log-rank test was used for comparisons of Kaplan-Meier curves. Cumulative incidence curves for non-relapse death and progression or relapse with or without death were constructed reflecting time to progression and time to non-relapse death as competing risks. Time to progression and time to non-relapse death were measured from the date of stem cell infusion. Competing risks analysis was also used to determine the cumulative incidence of GVHD, considering death without GVHD as a competing risk. The difference between cumulative incidence curves in the presence of a competing risk was tested using the Gray method [8]. Potential prognostic factors for survival, progression-free survival, progression, and non-relapse death were examined in the proportional hazards model as well as in the competing risks regression model [9]. The impact of GVHD on outcome was examined using proportional hazards model with GVHD as a time-dependent variable. Interaction terms including interaction with time were examined in the proportional hazards regression model. Proportional hazards assumption for each variable of interest was tested. All calculations were performed using SAS 9.2 (SAS Institute, Cary, NC) and R 2.10 (The CRAN project).

\section{RESULTS}

\section{Patients}

We studied 2185 consecutive patients who underwent allogeneic HSCT at DF/BWCC between 1/1/1996 and 6/30/2009. One hundred and seven patients were excluded because they had received a previous allogeneic HSCT. We were unable to generate appropriate geocoding data on 26 patients and 12 patients had missing relapse data. Lastly, we excluded 128 patients residing more than 6 hours driving time from DF/BWCC. The remaining 1912 patients were included in the analysis and their baseline demographic data is shown in Table 1. Twenty one percent of patients were lost to follow-up (defined as no information within 1 year of last date of data capture, with interval for data capture of 6 months), with no significant difference in this percentage by driving time quartile. 


\section{OS analysis of the entire cohort}

For the entire cohort, OS did not differ significantly between driving time quartiles, with 5year OS ranging from $44 \%$ to $36 \%(\mathrm{p}=0.22$ ) (Figure 1 ). In a multivariable analysis (including age, sex, ethnicity, median household income, disease, stage at HSCT, performance status at HSCT, conditioning intensity, graft source, donor type, GVHD prophylaxis, CMV status, year of transplantation, and whether HSCT was done on protocol), driving time from primary residence to DF/BWCC was not significantly associated with OS (hazard ratio $[\mathrm{HR}]$ for mortality for $4^{\text {th }}$ compared to $1^{\text {st }}$ quartile $=0.9, p=0.5$ ). However, this covariate failed to meet the proportional hazards assumptions; the effect on OS appeared stronger with increasing time from HSCT (see Figure 1). Indeed, driving time was significantly associated with OS when entered as a time-varying covariate in the model (HR of time-varying term for $4^{\text {th }}$ quartile compared with $1^{\text {st }}$ quartile $\left.=1.02, p=0.0007\right)$. This implies that the impact of driving time on OS becomes more pronounced further out from HSCT. Based on this finding, we performed a landmark analysis on all patients alive and free of disease at 12 months.

\section{Landmark analysis}

909 patients remained alive and free of disease at 1 year after HSCT. Baseline characteristics stratified by driving time from primary residence to DF/BWCC are shown in Table 2. Patients in the $2^{\text {nd }}$ and $3^{\text {rd }}$ quartiles had similar OS and thus were grouped together. Significant differences between driving time quartiles were found for race, income and donor-recipient sex match (Table 2). After a median follow-up for survivors of 48 months, the 5-yr OS was $76 \%$ (95\% confidence interval [CI], 68-81\%) in patients residing within 40 minutes, $72 \%$ (CI, 67-77\%) in those residing between 41 and 159 minutes and 65\% (CI, $57-72 \%)$ in patients residing 160 minutes or more away from DF/BWCC ( $\mathrm{p}=0.027)$ (Figure 2). Similarly, 5-yr DFS declined with increasing driving time to DF/BWCC (5y DFS 67\%, $67 \%$, and $58 \%$, respectively, $\mathrm{p}=0.038$ ). The $5 \mathrm{y}$ OS of patients alive and disease-free at 1 year but residing $>6$ hrs away (who were excluded from the above landmark analysis, as described in the Methods section) was 67\% (95\%CI 50-79\%), similar to the OS of patients living in the $4^{\text {th }}$ driving time quartile.

A multivariable Cox model for OS among patients alive and disease free at 12 months was constructed with the same covariates as above (see Table 3). The following were significantly associated with OS: age, disease type, stage at HSCT, donor type, graft source, conditioning, and driving time from primary residence to DF/BWCC. The HR for death for patients in the $4^{\text {th }}$ quartile, compared to the $1^{\text {st }}$, was $1.8(p=0.004)$, and the corresponding HR for relapse or death was 1.5 ( $p=0.03)$. Driving time remained significantly associated with overall survival in the landmark population when treated as a continuous variable $(\mathrm{HR}=1.002, \mathrm{p}=0.018)$. Notably, income, race and sex mismatch (which differed significantly among driving time quartiles) were not significant in this model (Table 3). Furthermore, in a separate analysis, state of residence was not an independent prognostic factor if driving time was included in the model (data not shown). In an additional landmark analysis of patients alive and disease free at 100 days, driving time in the $4^{\text {th }}$ quartile was still significantly associated with increased mortality compared to the $1^{\text {st }}$ quartile (HR for mortality compared to patients in the $1^{\text {st }}$ quartile $\left.1.3, p=0.019\right)$.

In competing risks regression models based on our landmark population of patients alive and disease free at one year, there appeared to be a trend for increased NRM in the $4^{\text {th }}$ quartile (HR 1.6, $p=0.07$ ), but not for relapse (HR 1.3, $p=0.2$ ). The addition of GVHD to the model did not affect the results of our landmark analysis. A history of severe (grade 3-4) acute GVHD had an adverse effect on OS (HR=1.6, $p=0.032$ ), while a history of chronic GVHD by 1 year did not $(\mathrm{HR}=1.1, p=0.4)$; however, the adverse effect of distance remained 
unchanged in a model that included acute and chronic GVHD (HR for driving time $\geq 160$ minutes compared to $\leq 40$ minutes $=1.8, p=0.003$ ).

\section{Post-HSCT care utilization}

To examine the possible causes of increased mortality in patients residing in geographically distant areas to the transplantation center, we performed an exploratory analysis of the impact of the number of visits at DF/BWCC on outcome. We considered the number of visits between day 100 and day 365 , reasoning that starting at day 100 should eliminate the variability associated with the length and complexity of the initial transplantation hospitalization, and stopping at day 365 since this was the beginning of the landmark analysis. The median number of clinical encounters with HSCT providers at DF/BWCC between day 100 and 365 after HSCT in patients alive and free of disease at one year was 11 (range, 0-38) (see Table 2). Patients in the $1^{\text {st }}$ quartile of driving time had significantly more clinical encounters (median 14) than patients in the $2^{\text {nd }}-3^{\text {rd }}$ (median 11 ) and the $4^{\text {th }}$ quartiles (median 8$)(\mathrm{p}<0.0001)$. We hypothesized that patients with an uneventful post-HSCT course would be seen on average every 4 to 5 weeks, corresponding to a total of 7 to 9 visits between day 100 and day 365 . We established this as our reference group $(n=205)$. In the landmark population, the 5 -yr OS of patients with 0 to 6 visits $(\mathrm{n}=152)$ was significantly inferior to that of the reference group, as was the OS of patients with greater than 9 visits $(\mathrm{n}=552)$ during this time period (Figure 3). Based on these findings, the number of visits between day 100 and 365 post-HSCT was incorporated in the landmark multivariable analysis. In this model, patients with $0-6$ visits and $>9$ visits had a significantly higher mortality compared to patients with 7-9 visits (HR 2.2 and 2.30, $\mathrm{p}=0.001$ and $<0.0001$, respectively). Driving time remained significant (HR in the $4^{\text {th }}$ compared to the $1^{\text {st }}$ quartile $=$ $2.2, p=0.0004)$. The results were similar if the reference range for an "appropriate" uneventful follow-up was set as 7-11 visits instead of 7-9, with 5y OS of 68\%,78\%, and $68 \%$, for patients with $0-6,7-11$, and $>11$ visits, respectively $(\mathrm{p}=0.055)$. There was no impact of visit history between 1 and 2 years on overall survival in a landmark analysis of patients alive and disease-free at 2 years.

The impact of visit number on survival appeared to be more marked in patients residing further away, as there appeared to be no adverse effect of low or high number of visits for patients residing within 40 minutes of the transplantation center, unlike for patients living more than 40 minutes away (not shown). In an attempt to estimate the potential number of patients receiving care in another HSCT center, we looked at the number of patients in the landmark population who had 0 visits between day 100 and 365 as these patients would have received the totality of their post-HSCT care elsewhere. Among 909 patients, $12(1 \%)$ patients had 0 encounters in this time period.

\section{DISCUSSION}

This study is the first to demonstrate, applying modern GIS technology in a large HSCT cohort, that a high ( $\geq 160$ minutes) driving time to transplantation center is associated with significantly worse OS after allogeneic HSCT. The effect of driving time on OS becomes apparent after 1 year, independently of other patient-, disease-, and HSCT-related variables, and is more pronounced on NRM than on relapse. Furthermore, our data suggests that increasing driving time to the transplantation center is associated with decreased post-HSCT care utilization at the transplantation center, which may contribute to the adverse impact of driving time on survival.

Despite an increasing number of studies addressing disparities in cancer survival based on geographic proximity to treatment center [4;10-15], few have focused on HSCT. In a recent retrospective study from Nebraska, primary area of residence was evaluated as an 
independent risk factor for OS in 1739 patients undergoing autologous and 267 patients undergoing allogeneic HSCT to treat selected hematologic malignancies between 1983 and 2004. Among the autologous HSCT patients, those from rural areas were found to have a higher mortality compared to those from urban areas. However, a comparable difference was not found among the patients undergoing allogeneic HSCT [6]. A smaller registry study from the province of Manitoba, Canada, failed to show significant survival differences between urban and rural patients undergoing autologous or allogeneic transplantation for hematologic malignancies [16]. These important studies may have been underpowered to detect differences in overall survival based on geographic proximity. Moreover, actual estimates of driving distance and time may more accurately reflect ease of access to care than the "rural versus urban" distinction and allow for greater analytical flexibility [17].

Our study, being retrospective in nature, is subject to selection bias. However, the observed differences in OS by driving time did not appear to be directly attributable to measurable differences in patient baseline characteristics. Although patients in the different quartiles had significantly different ethnic make-up, median household income, and donor-recipient sex matching (Table 2), none of these variables were significant in the multivariable analysis. Furthermore, relapse rate at 5 years and the occurrence of acute and chronic GVHD at one year were not statistically different across driving time quartiles. Lastly, the development of acute or chronic GVHD by 1 year did not appear to contribute to the observed differences in OS. Although we cannot exclude possible confounding by unmeasured socioeconomic variables, we hypothesize that the increase in mortality seen in patients living far away from the transplantation center could be due at least in part to decreased access to post-HSCTspecific care, and hence worse outcome from HSCT complications such as infections and GVHD that should ideally be managed by providers with transplantation-specific expertise.

This conclusion is supported by the fact that the number of visits to the transplantation center decreased with increasing driving time, a finding previously reported in other health care settings [5;18;19]. Moreover, patients seen less frequently than what one might consider an appropriate routine follow-up frequency ( $<7$ visits between day 100 and 365) had a significantly worse OS compared with our reference group (7-9 visits). The OS was also worse for patients with more frequent visits (>9), likely reflecting the fact that those patients were sicker and in greater need of care. Frequency of visits remained a significant predictor of OS after HSCT (independently of driving time) in the multivariable analysis. The choice of a cut-off for an "optimal" number of visits is naturally arbitrary. However, there appeared to be a similar, though less pronounced, effect if the "optimal" range was defined as 7-11 visits between day 100 and day 365 .

These findings are the first to suggest that enforcing a minimum follow-up schedule could potentially result in better outcomes in a transplantation center that serves a geographically varied population. The absolute number may vary based on surrounding geographic and socio-demographic factors as well as available regional healthcare expertise and resources for each HSCT center. Although this analysis is exploratory in nature, as it is subject to significant confounding, additional studies should be undertaken to confirm this important observation. Furthermore, measures such as local physician education, establishment of HSCT-specific outreach clinics, or the development of a telemedicine infrastructure, could be studied in an attempt to optimize HSCT outcomes. Ultimately, if our findings can be reproduced in other institutions and geographic settings, new knowledge derived from this area of research could have far-reaching implications on the delivery of post-HSCT care.

\section{Acknowledgments}

Study concept and design: Abou-Nassar, Armand, Antin. 
Acquisition of data: Abou-Nassar, Blossom, Armand.

Analysis and interpretation of data: Abou-Nassar, Blossom, Armand, Kim.

Drafting of the manuscript: Abou-Nassar, Armand, Kim, Blossom, Soiffer, Cutler, Ho, Koreth, Alyea, Antin

Supported in part by NIH grant CA142106, Jock and Bunny Adams Research and Education Endowment, CA.

\section{Reference List}

1. Rizzo JD, Wingard JR, Tichelli A, Lee SJ, Van Lint MT, Burns LJ, Davies SM, Ferrara JL, Socie G. Recommended screening and preventive practices for long-term survivors after hematopoietic cell transplantation: joint recommendations of the European Group for Blood and Marrow Transplantation, the Center for International Blood and Marrow Transplant Research, and the American Society of Blood and Marrow Transplantation. Biol Blood Marrow Transplant. 2006; 12(2):138-151. [PubMed: 16443512]

2. Horowitz MM, Przepiorka D, Champlin RE, Gale RP, Gratwohl A, Herzig RH, Prentice HG, Rimm AA, Ringden O, Bortin MM. Should HLA-identical sibling bone marrow transplants for leukemia be restricted to large centers? Blood. 1992; 79(10):2771-2774. [PubMed: 1586723]

3. Chan L, Hart LG, Goodman DC. Geographic access to health care for rural Medicare beneficiaries. J Rural Health. 2006; 22(2):140-146. [PubMed: 16606425]

4. Haynes RM, Bentham CG. The effects of accessibility on general practitioner consultations, outpatient attendances and in-patient admissions in Norfolk, England. Soc Sci Med. 1982; 16(5):561569. [PubMed: 7100988]

5. LaVela SL, Smith B, Weaver FM, Miskevics SA. Geographical proximity and health care utilization in veterans with SCI\&D in the USA. Soc Sci Med. 2004; 59(11):2387-2399. [PubMed: 15450711]

6. Rao K, Darrington DL, Schumacher JJ, Devetten M, Vose JM, Loberiza FR Jr. Disparity in survival outcome after hematopoietic stem cell transplantation for hematologic malignancies according to area of primary residence. Biol Blood Marrow Transplant. 2007; 13(12):1508-1514. [PubMed: 18022581]

7. Przepiorka D, Weisdorf D, Martin P, Klingemann HG, Beatty P, Hows J, Thomas ED. Consensus Conference on Acute GVHD Grading. Bone Marrow Transplant. 1994; 1995; 15(6):825-828. [PubMed: 7581076]

8. Gray R. A Class of K-Sample Tests for Comparing the Cumulative Incidence of a Competing Risk. The Annals of Statistics. 1988; 16(3):1140-1154.

9. Fine J, Gray R. A Proportional Hazards Model for the Subdistribution of a Competing Risk. Journal of the American Statistical Association. 1999; 94:496-509.

10. Campbell NC, Elliott AM, Sharp L, Ritchie LD, Cassidy J, Little J. Rural factors and survival from cancer: analysis of Scottish cancer registrations. Br J Cancer. 2000; 82(11):1863-1866. [PubMed: 10839303]

11. Jack RH, Gulliford MC, Ferguson J, Moller H. Geographical inequalities in lung cancer management and survival in South East England: evidence of variation in access to oncology services? Br J Cancer. 2003; 88(7):1025-1031. [PubMed: 12671698]

12. French J, McGahan C, Duncan G, Lengoc S, Soo J, Cannon J. How gender, age, and geography influence the utilization of radiation therapy in the management of malignant melanoma. Int J Radiat Oncol Biol Phys. 2006; 66(4):1056-1063. [PubMed: 16965863]

13. Dejardin O, Bouvier AM, Herbert C, Velten M, Buemi A, Delafosse P, Maarouf N, Boutreux S, Launoy G. Social and geographic disparities in access to reference care site for patients with colorectal cancer in France. Br J Cancer. 2005; 92(10):1842-1845. [PubMed: 15886707]

14. Pagano E, Di CD, Bona C, Baldi I, Gabriele P, Ricardi U, Rotta P, Bertetto O, Appiano S, Merletti F, Segnan N, Ciccone G. Accessibility as a major determinant of radiotherapy underutilization: a population based study. Health Policy. 2007; 80(3):483-491. [PubMed: 16781002]

15. Kim YE, Gatrell AC, Francis BJ. The geography of survival after surgery for colo-rectal cancer in southern England. Soc Sci Med. 2000; 50(7-8):1099-1107. [PubMed: 10714930] 
16. Paulson K, Lambert P, Bredeson C, Demers A, Nowatzki J, Richardson E, Rubinger M, Szwajcer D, Seftel MD. Does location matter? Rural vs urban outcomes after blood and marrow transplantation in a population-based Canadian cohort. Bone Marrow Transplant. 2010; 45(7): 1167-1173. [PubMed: 20010868]

17. Fortney J, Rost K, Warren J. Comparing Alternative Methods of Measuring Geographic Access to Health Services. Heath Services and Outcomes Research Methology. 2011; 1(2):173-184.

18. Edelman MA, Menz BL. Selected comparisons and implications of a national rural and urban survey on health care access, demographics, and policy issues. J Rural Health. 1996; 12(3):197205. [PubMed: 10162851]

19. Goodman DC, Fisher E, Stukel TA, Chang C. The distance to community medical care and the likelihood of hospitalization: is closer always better? Am J Public Health. 1997; 87(7):1144-1150. [PubMed: 9240104] 


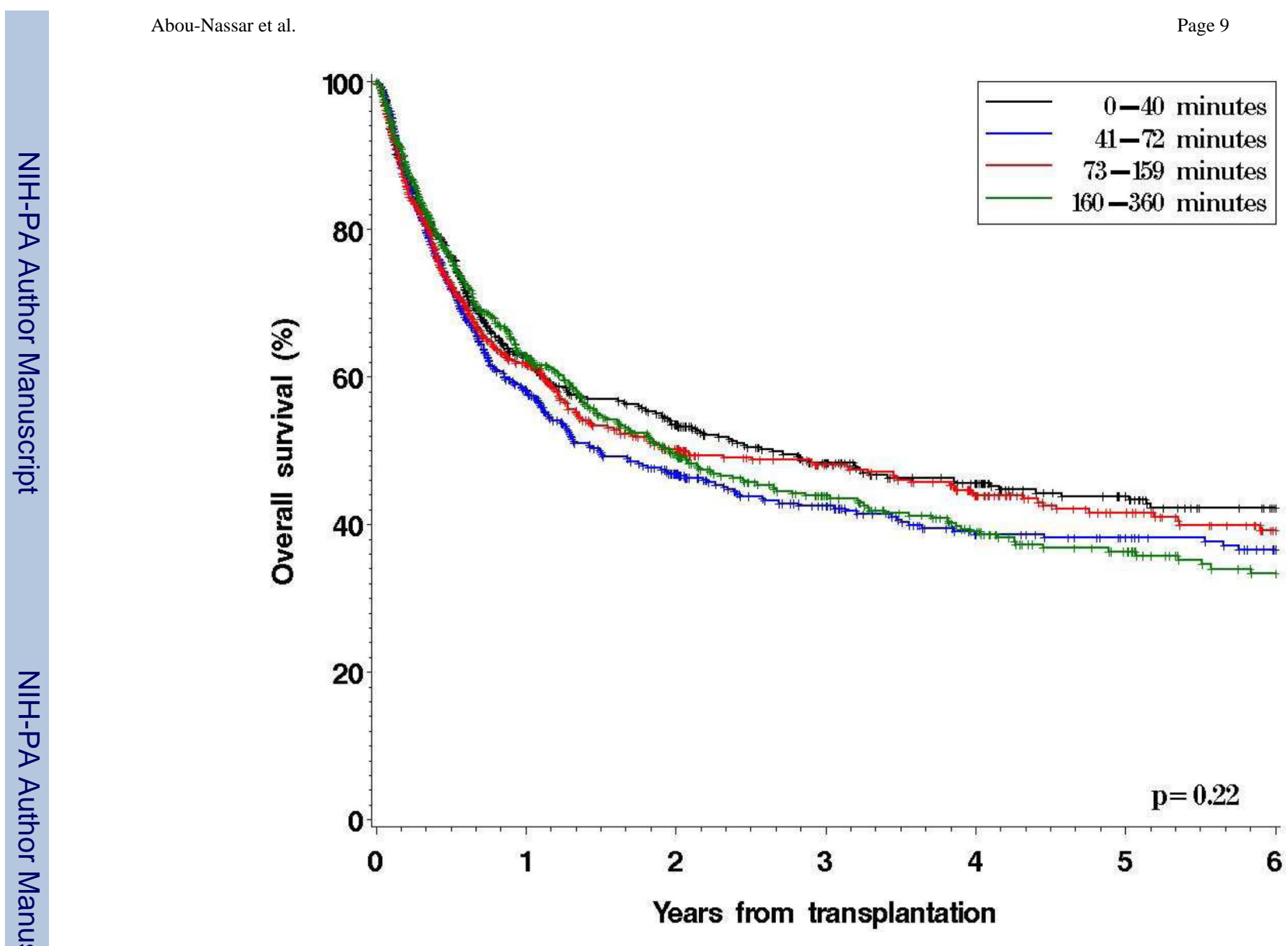

Figure 1.

Overall Survival by Driving Time Quartiles to DF/BWCC 


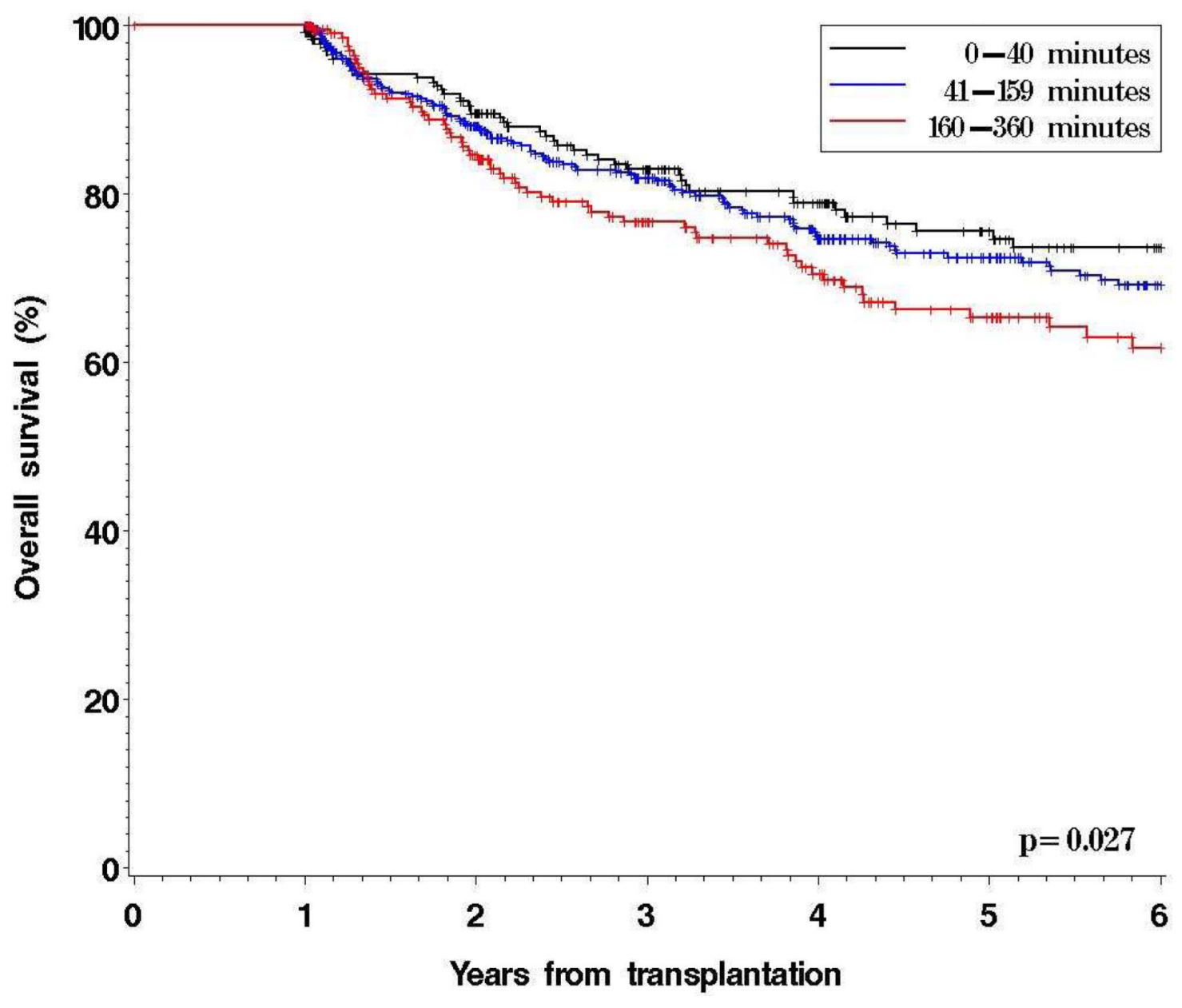

Figure 2.

Overall Survival by Driving Time to DF/BWCC for Patients Alive and Free of Disease at 12 Months: Landmark Analysis 


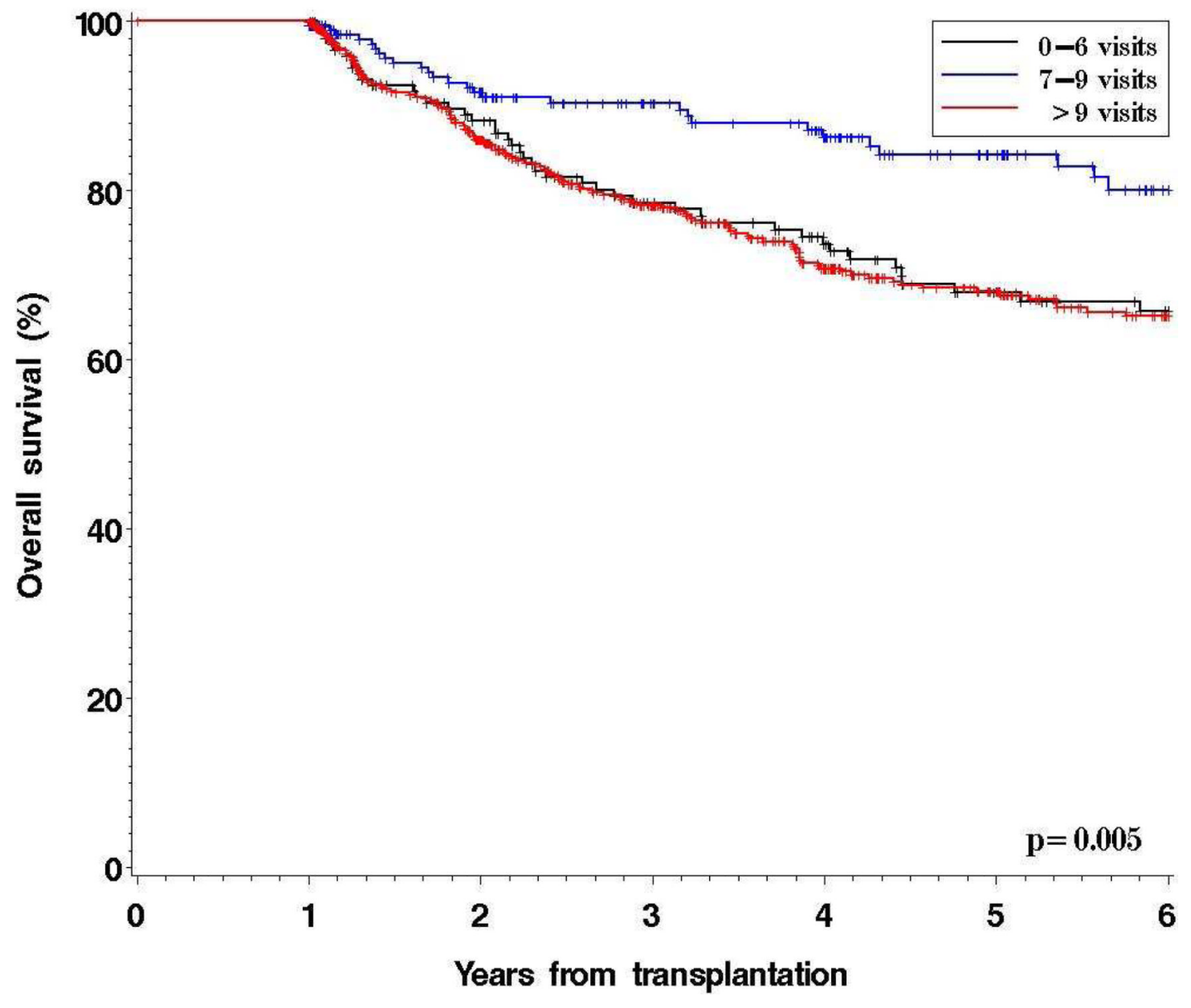

Figure 3.

Overall Survival According to Number of Visits to DF/BWCC Between Day 100 and 365 post allogeneic HSCT for Patients Alive and Free of Disease at 12 Months 
Table 1

Baseline characteristics

\begin{tabular}{|c|c|}
\hline Variable & N. $(\%)^{a}$ \\
\hline Number of patients & 1912 \\
\hline Driving time (median, range in minutes) & $72(2-358)$ \\
\hline Age (years) (median, range) & $47(17-73)$ \\
\hline \multicolumn{2}{|l|}{ Sex } \\
\hline Male & $1090(57)$ \\
\hline Female & $822(43)$ \\
\hline \multicolumn{2}{|l|}{ Race } \\
\hline Caucasian & $1779(93)$ \\
\hline Black/African-American & $42(2)$ \\
\hline Asian & $28(1)$ \\
\hline Other/unknown & $63(3)$ \\
\hline Median household income for zipcode of residence (median, range in thousands of dollars) & $51.7(16.4-154.4)$ \\
\hline \multicolumn{2}{|l|}{ Disease } \\
\hline AML & $634(33)$ \\
\hline ALL & $189(10)$ \\
\hline CML & $255(13)$ \\
\hline CLL & $121(6)$ \\
\hline MDS & $218(11)$ \\
\hline $\operatorname{MPD}^{b}$ & $32(2)$ \\
\hline Low grade $\mathrm{NHL}^{f}$ & $66(3)$ \\
\hline High grade $\mathrm{NHL}^{g}$ & $197(10)$ \\
\hline HL & $72(4)$ \\
\hline MM & $68(4)$ \\
\hline Benign hematologic disease & $54(3)$ \\
\hline Other & $6(0)$ \\
\hline \multicolumn{2}{|l|}{ Stage at SCT } \\
\hline $\mathrm{CR} 1 / \mathrm{CP} 1$ & $609(32)$ \\
\hline $\mathrm{CR}>1 / \mathrm{CP}>1$ & $274(14)$ \\
\hline Induction Failure & $274(14)$ \\
\hline $\mathrm{PR} / \mathrm{AP}$ & $323(17)$ \\
\hline Relapse/BC & $217(11)$ \\
\hline Untreated & $215(11)$ \\
\hline \multicolumn{2}{|l|}{ Treatment on protocol } \\
\hline Yes & $893(47)$ \\
\hline
\end{tabular}




\begin{tabular}{|c|c|}
\hline Variable & N. $(\%)^{a}$ \\
\hline No & $1019(53)$ \\
\hline \multicolumn{2}{|l|}{ ECOG performance status at HSCT $^{c}$} \\
\hline 0 & $416(43)$ \\
\hline 1 & $448(46)$ \\
\hline $2-3$ & $105(11)$ \\
\hline \multicolumn{2}{|l|}{ Donor match } \\
\hline MRD & $867(45)$ \\
\hline Non-MRD & $1045(55)$ \\
\hline MUD & $799(42)$ \\
\hline Mismatched & $246(13)$ \\
\hline Mismatched unrelated & $217(11)$ \\
\hline Mismatched related & $29(2)$ \\
\hline \multicolumn{2}{|l|}{ Graft source } \\
\hline PB & $1177(62)$ \\
\hline BM & $640(33)$ \\
\hline $\mathrm{PB}+\mathrm{BM}$ & $6(0)$ \\
\hline $\mathrm{UCB}$ & $89(5)$ \\
\hline \multicolumn{2}{|l|}{ Conditioning } \\
\hline Myeloablative & $695(36)$ \\
\hline Non-myeloablative/Reduced intensity & $1217(64)$ \\
\hline \multicolumn{2}{|l|}{ GVHD prophylaxis } \\
\hline $\mathrm{CnI}+/-\mathrm{Mtx}$ & $842(44)$ \\
\hline $\mathrm{CnI}+\mathrm{Rapa}+/-\mathrm{Mtx}$ & $756(40)$ \\
\hline $\mathrm{CnI}+\mathrm{MMF}$ & $66(3)$ \\
\hline T-cell depletion & $214(11)$ \\
\hline Other & $34(2)$ \\
\hline \multicolumn{2}{|l|}{ CMV serostatus ${ }^{d}$} \\
\hline Recipient or donor + & $1134(61)$ \\
\hline \multicolumn{2}{|l|}{ Sex matching $e^{e}$} \\
\hline Female to male & $448(24)$ \\
\hline Male to female & $414(22)$ \\
\hline Female to female & $402(21)$ \\
\hline Male to male & $639(34)$ \\
\hline Year of HSCT (median, range) & 2004 (1996-2009) \\
\hline Months of follow-up for survivors (median, range) & $41(4-163)$ \\
\hline
\end{tabular}

AML: Acute myeloid leukemia 
ALL: Acute lymphoblastic leukemia

CML: Chronic myelogenous leukemia

CLL: Chronic lymphocytic leukemia

MDS: Myelodysplastic syndrome

MPD: Myeloproliferative disorder

NHL: Non Hodgkin lymphoma

HL: Hodgkin lymphoma

MM: Multiple myeloma

CR: Complete remission

CP: Chronic phase

PR: Partial remission

AP: Accelerated phase

$\mathrm{BC}$ : Blast crisis

MRD: Matched related donor

MUD: Matched unrelated donor

PB: Peripheral blood

BM: Bone marrow

UCB: Umbilical cord blood

CnI: Calcineurin inhibitor

MTX: Methotrexate

Rapa: Rapamycin

${ }^{a}$ Percentages may not add to 100 because of rounding.

$b_{\text {Including mixed MPD/MDS. }}$

$c_{\text {Data missing on } 943 \text { patients. }}$

${ }^{d}$ Data missing on 41 patients.

Donor sex data missing on 9 patients.

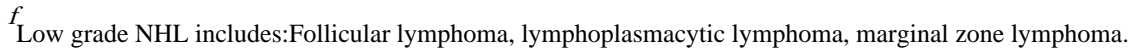

$g_{\text {High grade NHL includes all histologies not found in low grade NHL }}$ 


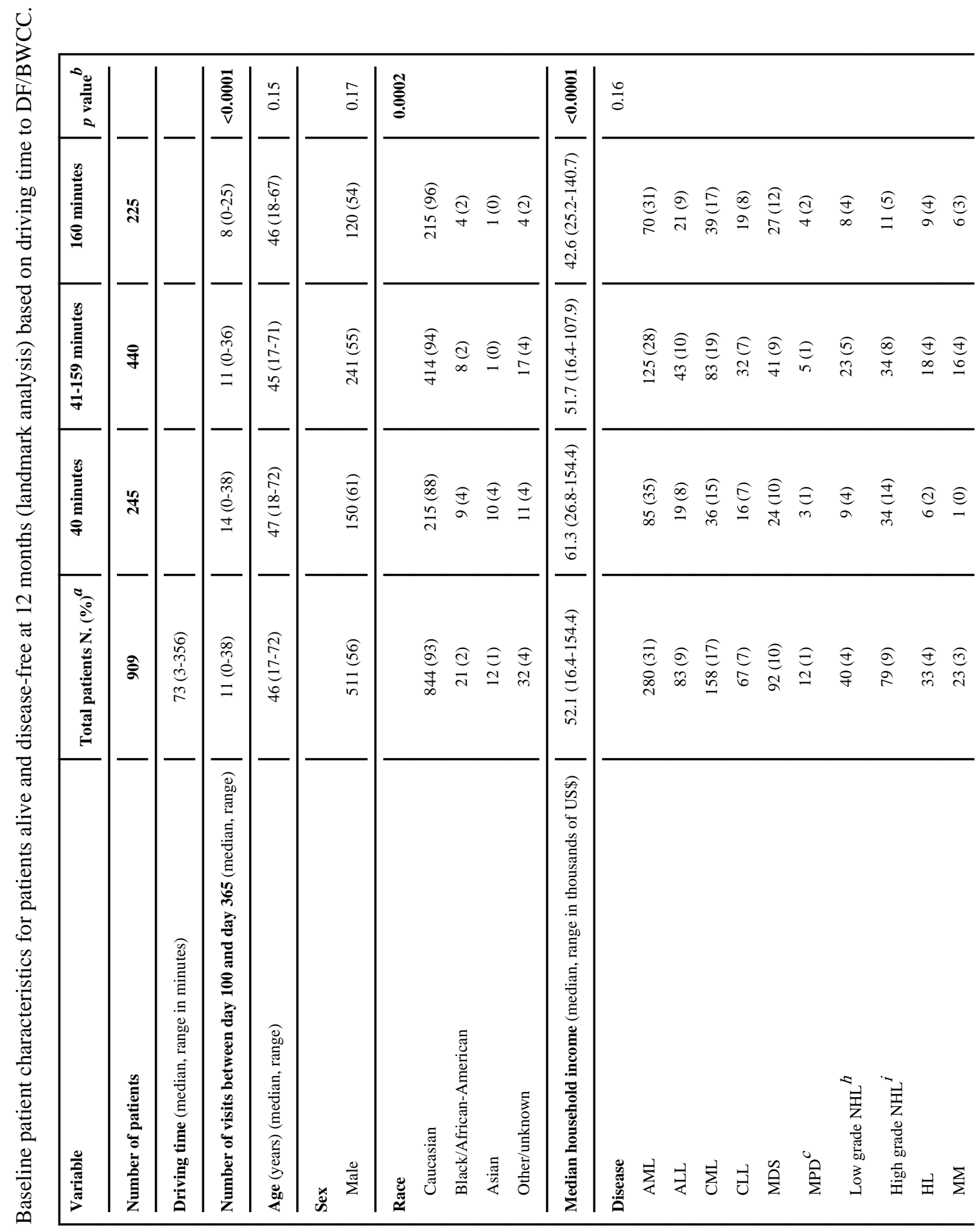

Biol Blood Marrow Transplant. Author manuscript; available in PMC 2013 May 01. 


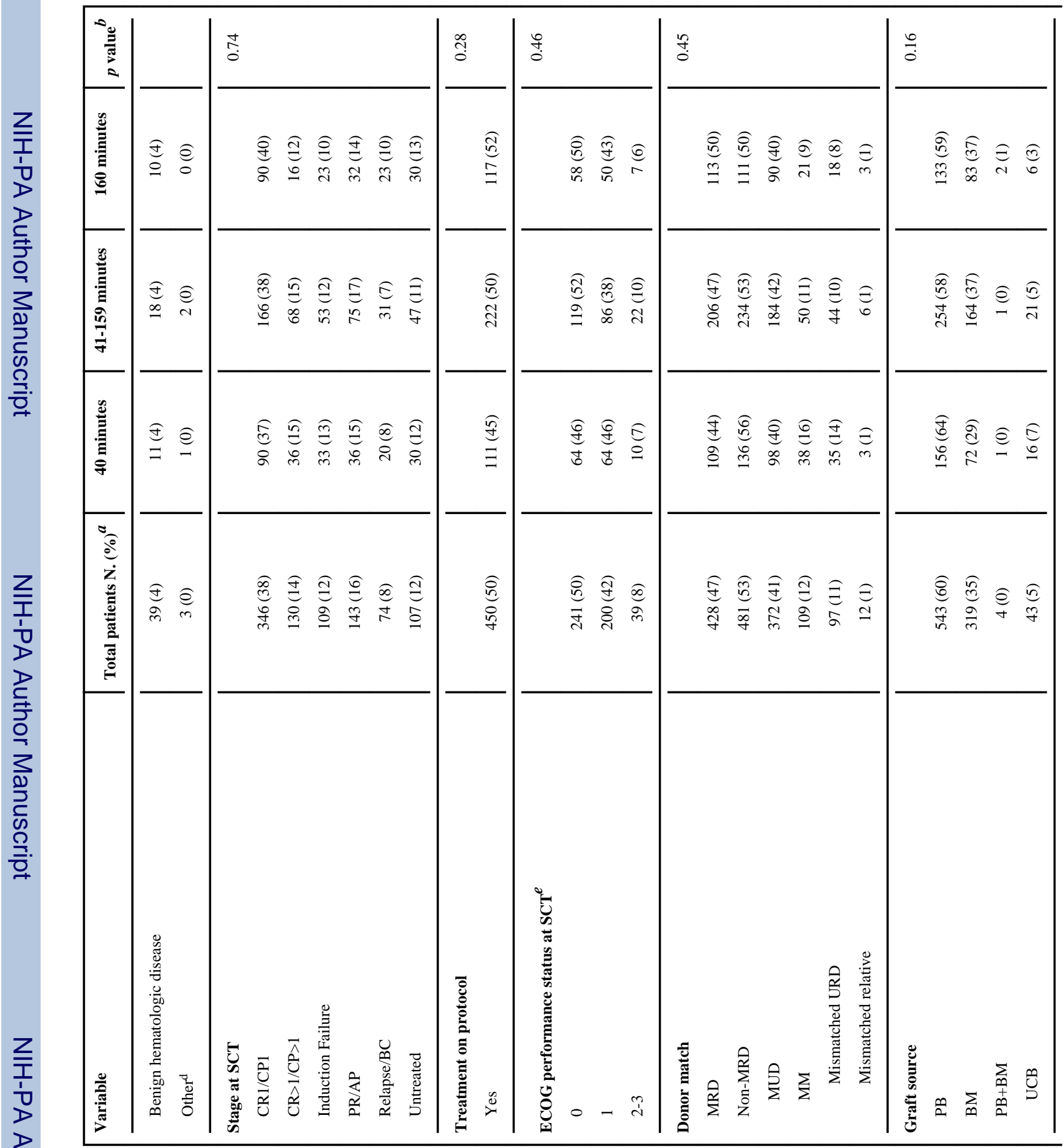




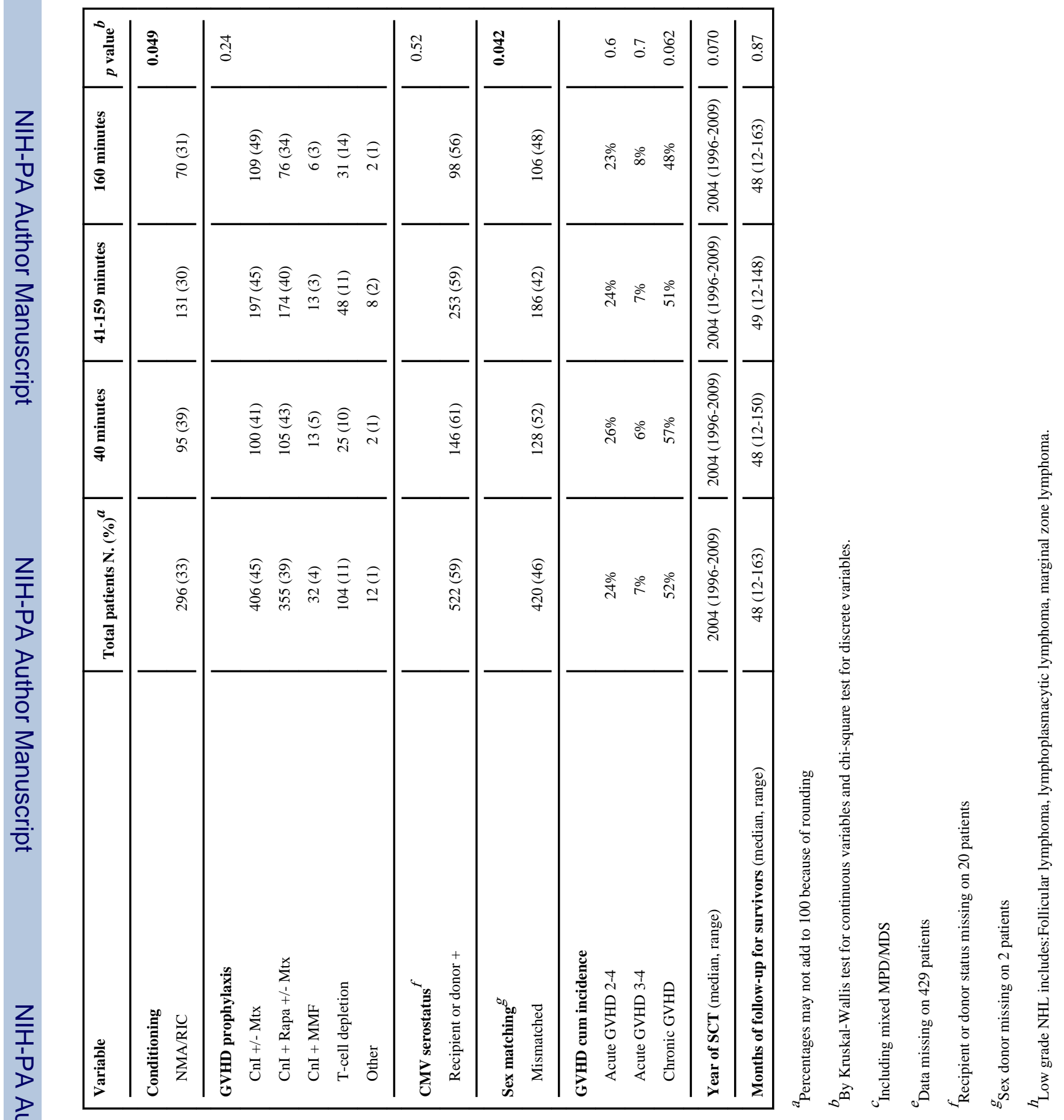




\begin{tabular}{|c|c|c|c|c|c|c|c|c|c|}
\hline$\sum_{\underline{z}}$ & $\therefore$ & $\stackrel{\infty}{0} \stackrel{0}{0}$ & $\overline{0}$ & 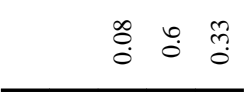 & oे & & $\overline{0}$ & $\tilde{c}$ & \\
\hline & $\cong$ & $\stackrel{\breve{\Xi}}{\cong} \stackrel{n}{\circ}$ & 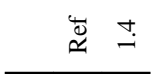 & 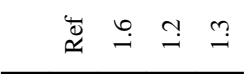 & ๘ै & $\ddot{\ddot{\Xi}}=$ & $\stackrel{+}{-}$ & 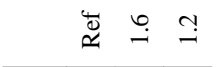 & \\
\hline $\begin{array}{l}\stackrel{0}{0} \\
\frac{0}{\sigma}\end{array}$ & 2 & กิ & t: & $\stackrel{\infty}{0} \stackrel{n}{0} \stackrel{3}{0}$ & ? & & ? & 仓̊̀. & \\
\hline & $\cong$ & $\ddot{\mathscr{\mathscr { U }}} \stackrel{\circ}{\circ} \stackrel{-}{-}$ & $\ddot{\mathscr{\Xi}} \hat{o}$ & 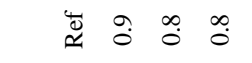 & $\ddot{\mathscr{\Xi}}$ & $\ddot{\ddot{\Xi}}$ & $\stackrel{\infty}{\infty}$ & 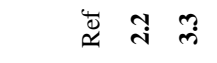 & \\
\hline E & 2 & 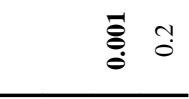 & $\stackrel{\infty}{n}$ & 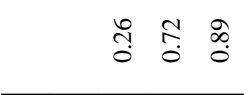 & $\stackrel{\infty}{\infty}$ & & $n$ & 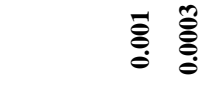 & \\
\hline & $\cong$ & 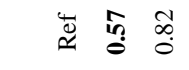 & $\stackrel{\breve{\Xi}}{\check{-}}$ & 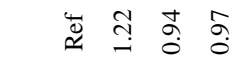 & $\begin{array}{ll}\breve{d} & \infty \\
\simeq & 0\end{array}$ & & $\stackrel{\infty}{-}$ & 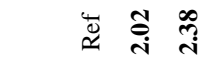 & \\
\hline o & 2 & 司 $\overline{\dot{\theta}}$ & ชี & 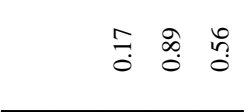 & oे & & ָ̦ & 产 & \\
\hline & $\cong$ & 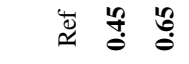 & 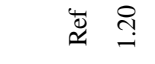 & 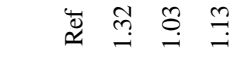 & 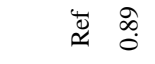 & $\stackrel{\Xi}{\simeq}$ & $\rightrightarrows$ & 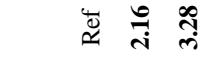 & \\
\hline 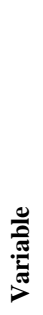 & & 喿员导守 & 苛 & 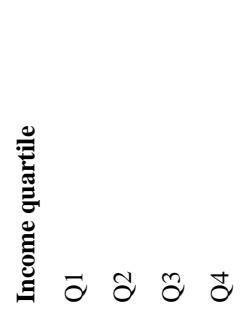 & 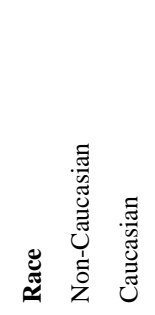 & 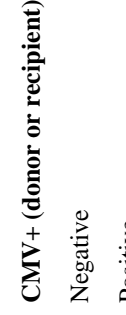 & & 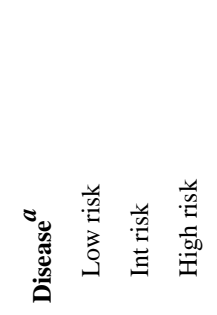 & 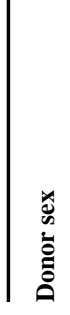 \\
\hline
\end{tabular}

Biol Blood Marrow Transplant. Author manuscript; available in PMC 2013 May 01. 


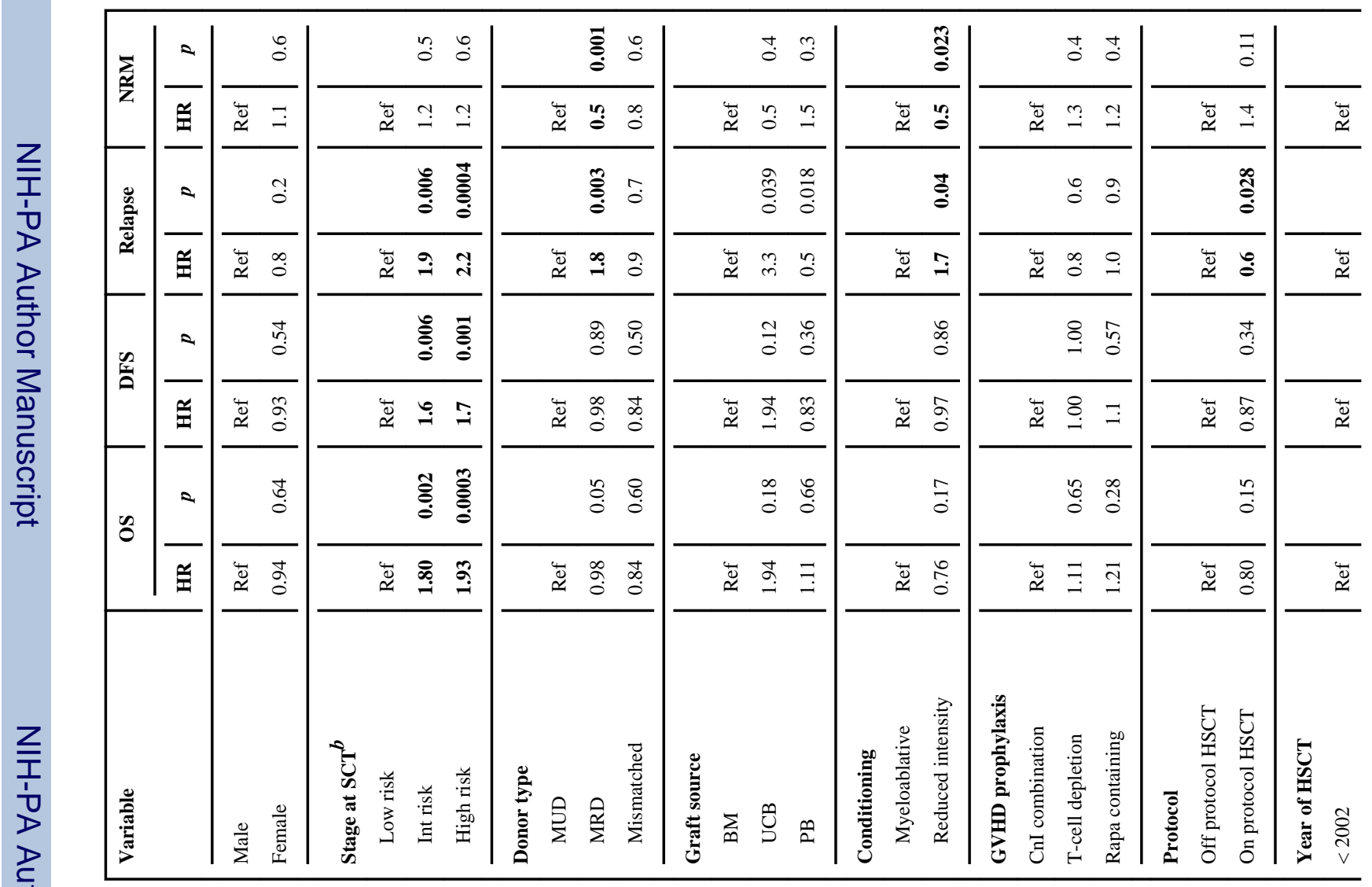




\begin{tabular}{|c|c|c|c|}
\hline$\sum$ & 2 & $\stackrel{\infty}{0}$ & $\begin{array}{ll}1 & 0 \\
0 & 0 \\
0\end{array}$ \\
\hline & $\cong$ & $\exists$ & 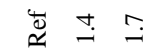 \\
\hline
\end{tabular}

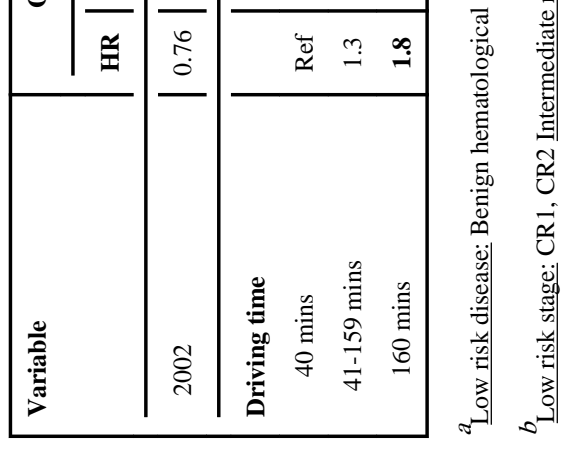

